\title{
Surveying rip current survivors: preliminary insights into the experiences of being caught in rip currents
}

\author{
D. Drozdzewski ${ }^{1}$, W. Shaw ${ }^{1}$, D. Dominey-Howes ${ }^{2}$, R. Brander ${ }^{1}$, T. Walton ${ }^{2}$, A. Gero ${ }^{3}$, S. Sherker ${ }^{4}$, J. Goff ${ }^{2}$, and \\ B. Edwick ${ }^{1}$ \\ ${ }^{1}$ School of Biological, Earth and Environmental Sciences, University of New South Wales, Sydney, NSW 2052, Australia \\ ${ }^{2}$ Australia-Pacific Tsunami Research Centre and Natural Hazards Research Laboratory, School of Biological, Earth and \\ Environmental Sciences, University of New South Wales, Sydney, NSW 2052, Australia \\ ${ }^{3}$ Institute of Sustainable Futures, University of Technology, Sydney, NSW 2007, Australia \\ ${ }^{4}$ Surf Life Saving Australia (SLS), Rosebery, Sydney, NSW 2018, Australia
}

Correspondence to: D. Drozdzewski (danielled@unsw.edu.au)

Received: 14 October 2011 - Revised: 7 January 2012 - Accepted: 11 January 2012 - Published: 26 April 2012

\begin{abstract}
This paper begins a process of addressing a significant gap in knowledge about people's responses to being caught in rip currents. While rip currents are the primary hazard facing recreational ocean swimmers in Australia, debate exists about the best advice to give swimmers caught in rip currents. Such surf rescue advice - on what to do and how to respond when caught in a rip - relies on empirical evidence. However, at present, knowledge about swimmers reactions and responses to rip currents is limited. This gap is a considerable barrier to providing effective advice to beach goers and to understanding how this advice is utilised (or not) when actually caught in the rip current.
\end{abstract}

This paper reports the findings of a pilot study that focussed on garnering a better understanding of swimmers' experiences when caught in rip currents. A large scale questionnaire survey instrument generated data about rip current survivors' demographics, knowledge of beach safety and their reactions and responses when caught in a rip current. A mix of online and paper surveys produced a total of 671 completed surveys. Respondents were predominantly an informed group in terms of rip current knowledge, beach experience and had a high self-rated swimming ability. Preliminary insights from the survey show that most respondents recalled a "swim across the rip/parallel to the beach" message when caught in the rip and most escaped unassisted by acting on this message. However, while nearly a quarter of respondents recalled a message of "not to panic", short answer responses revealed that the onset of panic inhibited some respondents from recalling or enacting any other type of beach safety message when caught in the rip current. Results also showed that despite the research sample being younger, competent and frequent ocean swimmers, they were more likely to swim at unpatrolled beaches and outside of the red and yellow safety flags. Moreover, they were still caught in a rip current and they panicked. The findings of this study have significant implications for a range of demographic groups of differing beach safety knowledge and swimming ability who may be caught in rip currents behave, we know very little about how beach goers may respond to being caught in them.

\section{Introduction and aims}

Rip currents are strong, narrow seaward flows of water that occur on any beach that experiences waves breaking across a wide area (Short, 2007; MacMahan et al., 2011) (Fig. 1). They can quickly carry unsuspecting swimmers significant distances away from the beach, often against their will, and thus represent a significant global beach hazard. In Australia, rip currents are the primary cause of beach drownings with 21 drownings per year since 2004 (SLS, 2011). Moreover, rip related drownings comprise 23 percent of drowning deaths in Australia since 2004 (SLS, 2011). However, it should be noted that these values are likely under-estimated given that accurate incident reporting of rip current drowning is difficult and many beach drowning due to unknown causes are likely due to rip currents. Gensini and Ashley (2010) describe a similar scenario for rip current drowning fatalities in the United States. For this reason, we simply do not know the actual number of people who drown in rip currents globally, although Fletemeyer and Leatherman (2010) estimate that the annual number exceeds 1000 .

Our scientific understanding of the physical behaviour of rip currents continues to improve (MacMahan et al., 2006; Dalrymple et al., 2011) and a number of studies have 


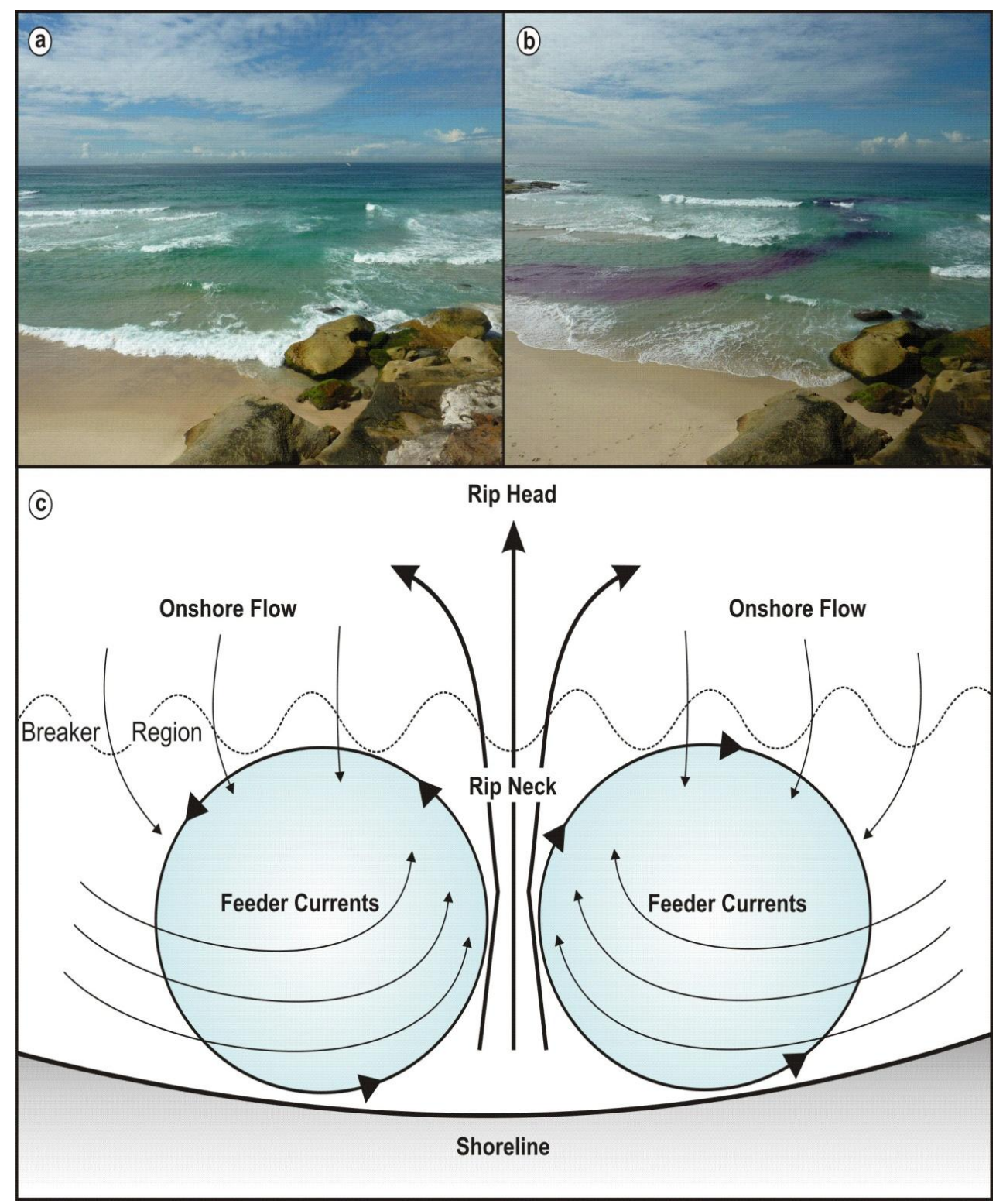

Fig. 1. Most rip currents sit in deeper channels between adjacent sandbars and appear as a dark gap between breaking waves (a) A release of purple dye (b) illustrates the extent of rip current flow from the shoreline through the surf zone. The idealised schematic in (c) shows that water transported onshore by breaking waves is either recirculated by rip currents within the surf zone or carried seaward through a narrow rip neck where it dissipates in an expanding rip head.

investigated the general behaviour and safety awareness of beachgoers (see for example: Ballantyne et al., 2005; Moran, 2006, 2008; Wilks et al., 2007; McCool et al., 2008, 2009; Morgan et al., 2008; Sherker et al., 2010). Recently, several studies have attempted to link the physical behaviour of rip currents with the incidence of drowning and swimmer response to being caught in rip currents (MacMahan et al., 2010; Houser et al., 2011; Miloshis and Stephenson, 2011). These studies have contributed to an ongoing debate amongst rip current scientists and beach safety practitioners (Brander and MacMahan, 2010; Brander et al., 2011) regarding the most appropriate response swimmers caught in rip currents should take: should they actively swim parallel to the beach to escape the rip current or should they adopt a passive approach and simply stay afloat and signal for help? At present there appears to be no resolution to the debate.

This is in no small part due to the fact that no study has specifically targeted the social and demographic characteristics, fundamental surf knowledge and the responses of beachgoers who have actually been caught in rip currents - the 
"rip current survivors". Such fundamental gaps in knowledge stand as a primary barrier to designing effective rip hazard risk communication strategies.

To begin addressing these gaps, this research piloted survey methodologies to better understand peoples' experiences being caught in rip currents. The findings of the pilot study reported in this paper concern both the trialling of the method - the types of questions we asked and how we asked them - as well as the results - the answers to the survey questions. A Questionnaire Survey Instrument (QSI) was developed to gather data on the demographic characteristics, perceptions, surf knowledge and responses of people who have been caught in rip currents, and survived. An online and paper copy of the questionnaire were trialled via different dissemination outlets. We sought to gain a better understanding of the factors that influence peoples' perceptions of the rip current hazard and their likely actions when caught in a rip current. Five primary research questions were addressed:

1. Are there specific groups of people more likely to be caught in rip currents and what are the demographic characteristics of these groups?

2. How did respondents react when they were caught in a rip current?

3. What safety messages were recalled when people were caught in a rip current?

4. What was the overall experience of respondents caught in rip currents?

5. What safety messages regarding rip current escape were believed to be the most achievable?

The outcomes of this research will provide a research template informing a larger project about rip current dynamics and the characteristics and experiences of rip current survivors - including their perceptions of the rip current risk. Successful risk management requires both effective and timely hazard information and a "risk aware" and responsive public (Bird and Dominey-Howes, 2006, 2008; DomineyHowes and Goff, 2010). In order to reduce the incidence and impacts of rip current related drownings and rescues and to set a clear agenda for rip current education, it is essential to understand how and why people are caught in rip currents and their responses to the hazard. This research will help inform the design of future rip current education and awareness materials.

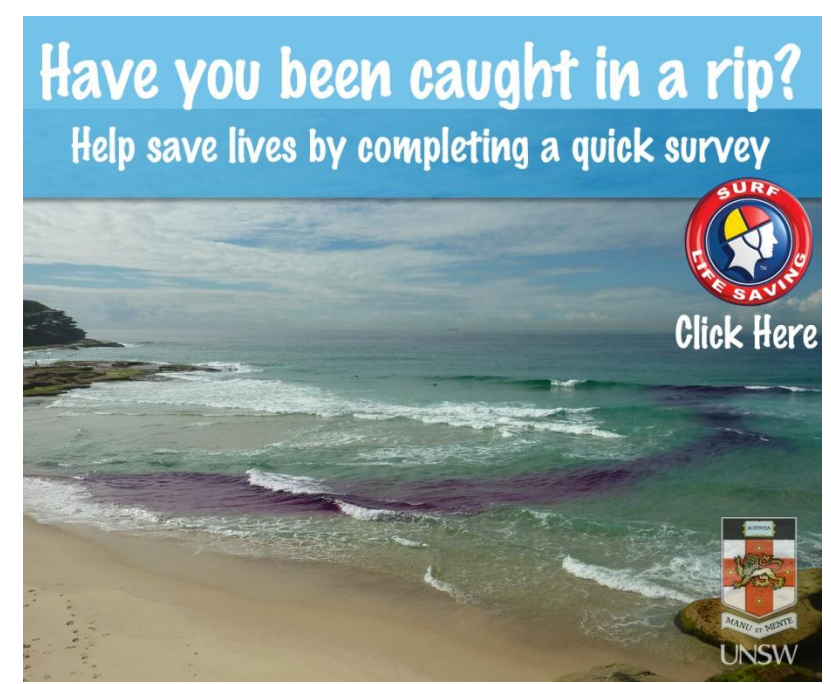

Fig. 2. The interactive advert used on websites for the online rip current survivor survey.

\section{Methods}

The QSI generated data about swimmers who have previously been caught in a rip current and survived, either through rescue or self-rescue. Human Ethics Clearance was sought and granted from the University of New South Wales (UNSW) Human Ethics Panel (no. 1424). Two distribution methods of the QSI were utilised.

The first method involved the design and circulation of an online survey instrument ${ }^{1}$. The online survey was initially trialled with staff from the School of Biological, Earth and Environmental Sciences at the University of New South Wales, Sydney, Australia. It was subsequently refined and distributed via an interactive advert (Fig. 2) at the following internet websites: (i) the Science of the Surf website (www.scienceofthesurf.com); (ii) the Surf Life Saving Australia (SLS) Beach Safe website via the rip currents portal(www.beachsafe.org.au); (iii) the Aquabumps website daily email on 21 January, 2011(www.aquabumps.com.au); and (iv) the UNSW Faculty of Science website (http://www. science.unsw.edu.au/).

The online survey was also a key component of the first "Rip Current Awareness Day" (6 February, 2011), a joint venture between SLS and UNSW, held in Australia. Rip Current Awareness Day and the online survey were promoted by the Australian Broadcasting Corporation (ABC) in the form of a 30 second Public Service Announcement, which ran at various times on ABC Radio 702 (Sydney, NSW based) and ABC State Radio in the 10 days prior to, and one week following, 6 February, 2011. Listeners were directed to the www.beachsafe.org.au website to complete the survey.

\footnotetext{
${ }^{1} \mathrm{~A}$ copy of the survey can be obtained by emailing the corresponding author.
} 
The second distribution method entailed use of a printed version of the survey, which was distributed at three popular beach locations within the greater Sydney, New South Wales (NSW) region: Bondi Beach, Freshwater Beach and Avoca Beach. The beaches were chosen as they are all characterised by the presence of rip currents, are patrolled by both professional lifeguards and volunteer lifesavers, are subject to rip current rescues and are visited by a diverse range of beach users.

In total, 671 survey responses were analysed in this study. Thirty-nine surveys were obtained from face to face surveying and 632 using the online survey instrument. Approximately 80 percent of the online surveys were derived from the Aquabumps advertisement. Aquabumps is a surf and beach photography website with a focus on Bondi Beach and themes of surf/beach culture and lifestyle. Our survey advert was part of a daily email sent out to 40000 subscribers (at the time of our advert). The subscribers to the website have an interest in beaches and surf culture.

\subsection{Survey design and data analysis}

The QSI comprised twenty-five questions - a mix of closedresponse and multi-part questions - to generate quantitative data (statistics) and qualitative data (from short answer questions). Quantitative questions generated data using tick boxes and Likert scales, which provided graded responses (such as strongly agree to strongly disagree).

The survey was divided into three parts. The first part sought demographic information relating to country of birth, age, place of residence, as well as swimming frequency and ability. The second part focused on ascertaining the respondent's knowledge of beach safety. Questions included describing a rip current, what to do when caught in a rip current, sources of information about rip current safety and the identification of rip currents in three photographic recognition questions. Within these questions, reference was made to a set of red and yellow beach flags, which in Australia designate safer swimming areas on beaches patrolled by professional lifeguards and volunteer lifesavers. The third part of the survey comprised questions about the respondent's experience of being caught in the rip current. Qualitative data was generated using open-ended short answer questions that enabled respondents to detail their experiences of being caught in the rip current. For example, participants were asked to specify and describe their immediate response to being caught in the rip current, what it "felt" like being caught, what they did to survive and their responses to being caught. By prompting the respondents to describe their own experiences, answers were not restricted or unnecessarily categorised by pre-determined options.

The online survey tool generated basic frequency data (percentages only). The quantitative data from close-ended questions was analysed in Microsoft EXCEL and SPSS (Statistical Package for the Social Sciences). The potential inter- relationships between the variables were tested using a combination of socio-demographic information and closed-ended responses about rip current experiences. For example, a respondent's age was tested against whether they were swimming between the flags (as a safe and recommended action) or at an unpatrolled beach, when caught in the rip current. There were eight qualitative open-responses in the survey. These responses were coded and themed using QSR NViVO - a qualitative data analysis program that aids in the coding of text responses into themes (Bazeley, 2007). The frequencies of these themes were also ascertained.

\section{Results and discussion}

As this paper examines the outcomes of a pilot study that surveyed rip current survivors, we have sought to shift the focus from solely reporting numbers, to also explaining the types of questions asked and why they were asked. The results and discussion have thus been combined enabling a more nuanced examination of the key themes emerging from the data.

\subsection{Demographics}

Males were overrepresented (63 percent of respondents) in the survey sample $(n=671)$, across almost all age categories, but particularly among those 35 to $45 \mathrm{yr}$ of age. The majority of respondents (77 percent) indicated Australia as their country of birth, with most living in NSW (76.7 percent). The majority of these listed their place of residence as within and around Sydney's eastern suburbs. The remaining 23 percent of non-Australian respondents were grouped according to the Australian Bureau of Statistics (ABS) Standard Classification of Countries (ABS, 2008). Respondents born in the UK and Ireland made up 45.5 percent of the non-Australian respondents, followed by North Americans (12.8 percent), Europeans (12.8 percent), New Zealanders and others. Non-Australian born respondents tended to share similar responses with Australian-born counterparts when asked questions about beach safety but it is not known if and/or how long these respondents had lived in Australia. However, more Australian-born respondents remembered a beach safety message than overseas-born respondents.

\subsection{Swimming characteristics}

Results indicate that the research sample were frequent swimmers with previous swim training, who self-identified as competent swimmers (Table 1). Sixty-four percent of respondents swam at a beach once per week or more. Sixtyfive percent of respondents believed their swimming ability to be competent to highly competent. Ninety-one percent of respondents had undertaken mostly pool-based swimming lessons, with the majority of these occurring over $15 \mathrm{yr}$ ago. 
Table 1. Respondent's swimming frequency and ability $(n=671)$.

\begin{tabular}{ll}
\hline $\begin{array}{l}\text { How often do you swim } \\
\text { at the beach during summer? }\end{array}$ & Response \% \\
\hline Everyday & 13.7 \\
1-3 times a week & 32.5 \\
More than 3 times a week & 17.6 \\
1-3 times a month & 19.4 \\
More than 3 times a month & 9.1 \\
Outside summer/other times of year & 7.6 \\
\hline Self-rated swimming ability & Response \% \\
\hline One (unable to swim) & 1.2 \\
Two & 5.4 \\
Three & 28.2 \\
Four & 37.1 \\
Five (highly competent) & 28.2 \\
\hline Have you had swimming & Response \% \\
lessons or swimming training? & \\
\hline Yes & 90.8 \\
No & 9.2 \\
\hline
\end{tabular}

\subsection{Rip current knowledge}

A person's ability to identify a rip current may be an important factor in determining why people get caught in rip currents. Eighty-four percent of respondents believed they could accurately identify a rip current. In the online survey, three photographs were included, the first had one rip, the second did not have a rip, and the third photo had two rips. Seventy-seven percent of the online survey respondents successfully identified all the rip currents in the photos with only 4.6 percent getting none or 1 out of 3 correct. The respondents therefore represented an informed group in terms of their ability to identify a rip current.

Rip current safety messages have been promoted through various means by beach safety practitioners for many years in many countries (Brander and MacMahan, 2011). It is useful to ascertain what information is remembered by beachgoers and whether this information represents a single consistent message, related messages, or mixed messages. Respondents were asked if they knew how to respond when caught in a rip current. Most respondents (63.5 percent) recalled at least one rip current safety message. The active response of "swim sideways to the rip/parallel to the beach" was clearly the most common message remembered (Fig. 3). However, at least four other messages received more than 20 percent of total responses. Respondents' comments suggest confusion regarding the mixed safety messages:
Do you know what to do when caught in a rip current?

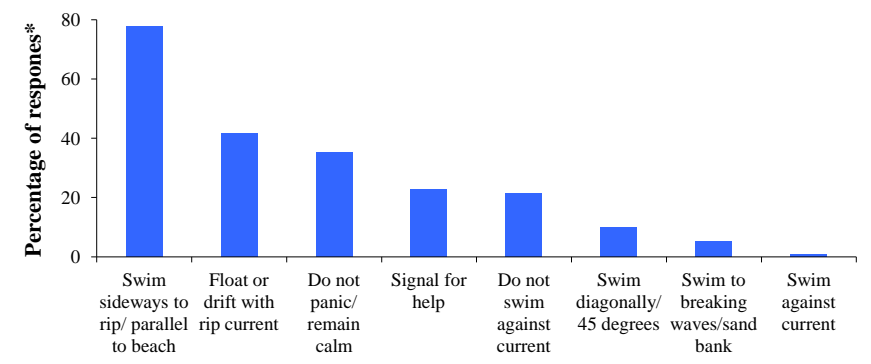

Fig. 3. Do you know what to do when caught in a rip current? $(n=662) .{ }^{*}$ These results are based on percentages of total valid responses for this question (Q17) and may total more than 100 percent because respondents' responses could have been coded into more than one theme.

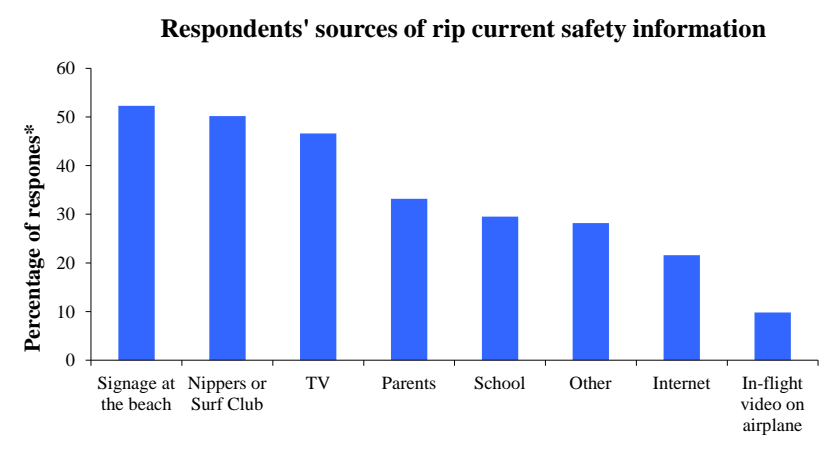

Fig. 4. Respondents' sources of rip current safety information. * These results are based on percentages of total valid responses for this question (Q18) and may total more than 100 percent because respondents could tick more than one response.

I think you're supposed to let it carry you out and then swim back in once you are out of the rip. I have also heard that you should swim "across" it (Respondent \#494, 3 February 2011).

Relax, float and go along with rip beyond the breaker zone and swim parallel to $t$ he beach along with the waves (Respondent \# 581, 29 January 2011).

Results showed that there was no single prominent information source about rip current safety (Fig. 4). In fact, the three most reported sources represent different avenues of information dissemination. First, "signage at the beach" refers to warning signs on the beach, which represents "on site" information (52 percent of responses). Second, "Surf Life Saving Clubs" (50 percent of responses) are popular community based organisations in Australia staffed by adult volunteers who are trained to become patrolling surf lifesavers. Most clubs also have a "Nippers" program for children. Rip current education is part of a learned process in both groups. The third most cited response, "television" is a passive education source (46.6 percent of responses). 
Table 2. Where respondents were swimming when they were caught in a rip current and if they signalled for a lifeguard for assistance.

\begin{tabular}{ll}
\hline Were you at a patrolled beach? $(n=664)$ & Response \% \\
\hline Yes & 59.2 \\
No & 28.8 \\
Out of hours or season & 6.8 \\
Sometimes & 4.2 \\
Not sure & 1.1 \\
\hline Were you between the flags? $(n=663)$ & Response \% \\
\hline Yes & 21.7 \\
No & 73.3 \\
Sometimes & 2.9 \\
Not sure & 2.1 \\
\hline Before signalling for the lifeguard did you try & Response \% \\
to swim out of the rip current? $(n=157)$ & \\
\hline Yes & 81.3 \\
No & 18.8 \\
\hline
\end{tabular}

\subsection{Respondents' rip current experiences}

The third part of the survey sought detail on respondents' overall experiences on being caught in a rip current. Given that most respondents (63.5 percent) recalled at least one rip current safety message, we sought to determine whether swimmers took this information with them to the beach. Respondents were first asked about their choice of swimming location including whether or not they were swimming between the flags, and whether they were at a patrolled beach when they were caught in a rip current. While the majority of respondents were at a patrolled beach (59 percent), 73 percent were swimming outside the flags (Table 2). The decision to swim outside of the flags and to at least initially attempt self-escape (81.3 percent of responses) from the rip current may suggest a certain level of over-confidence amongst these respondents.

To determine what factors influenced swimming location, swimming location was correlated against age (Fig. 5). Almost 40 percent of respondents 18 to $25 \mathrm{yr}$ of age were at an unpatrolled beach when they were caught in a rip current. In contrast, only 20 percent of respondents 55 to $64 \mathrm{yr}$ of age were at an unpatrolled beach when they were caught in a rip current. A lower percentage of respondents aged 65 and over swam outside the flags. These results indicate that older respondents are more likely to swim between the flags and signal for help. Younger respondents were more likely to swim at unpatrolled locations and not signal for help when caught in a rip current.

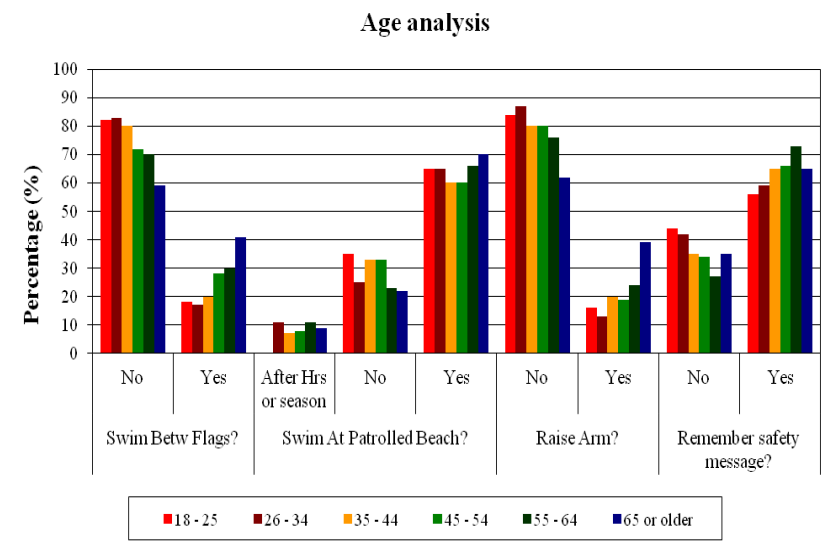

Fig. 5. Age as an independent variable in respondents' choices of swim location, rescue and remembrance of safety messages.

Feeling of being caught in a rip current

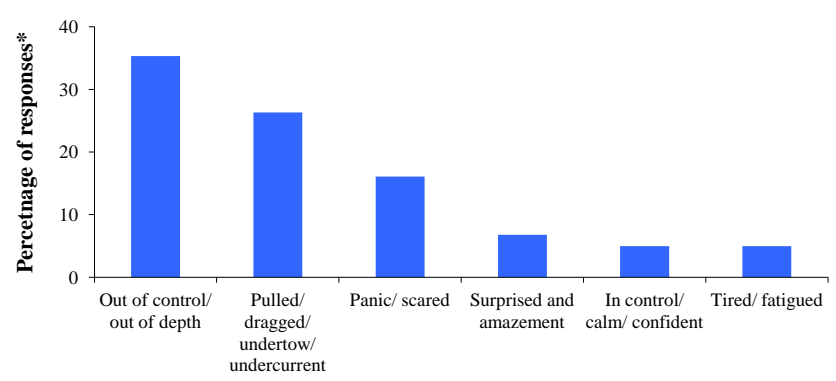

Fig. 6. Respondents comments on what it felt like to be caught in the rip current $(n=665)$. ${ }^{*}$ These results are based on the frequency of coded themes for Q20, and are represented as a percentage of the total no. of valid responses. Respondents' responses could have been coded into more than one theme.

\subsubsection{Respondents' feelings and responses to being caught in the rip current}

In a short-answer question, respondents were asked to describe what it "felt" like being "caught" in the rip current. Using a latent coding analysis, six major themes were identified (Fig. 6). Most commonly, respondents cited feeling "out of control/out of depth" (37 percent of responses), and of being "pulled/dragged" (28 percent responses). These results suggest that despite the majority of respondents selfidentifying as confident swimmers, and being well versed in rip current safety messages, the actual experience of being caught in the rip overwhelmed this ability and knowledge. As one respondent commented:

You are supposed to swim to one side of the current and not try to swim against it. This advice sometimes goes out the window when you are initially caught (Respondent \# 486, 2 February 2011). 


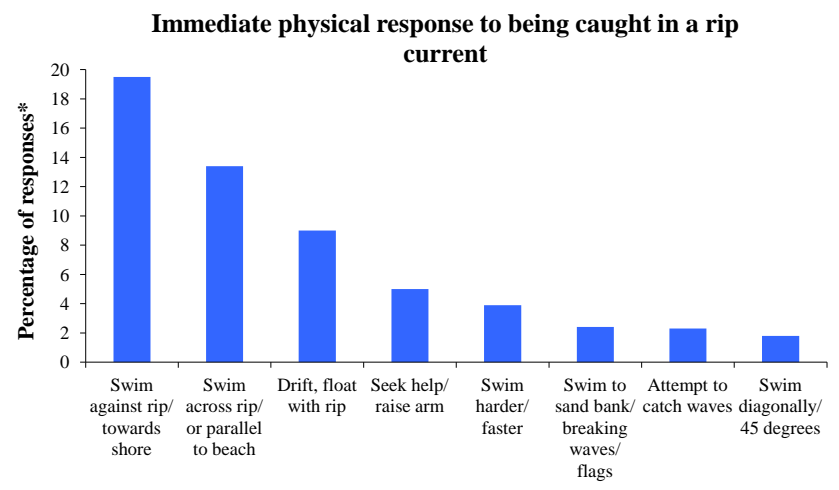

Fig. 7. Physical responses to being caught in the rip current $(n=$ $665) .{ }^{*}$ These results are based on the frequency of coded themes for Q21, and are represented as a percentage of the total no. of valid responses. Respondents' responses could have been coded into more than one theme.

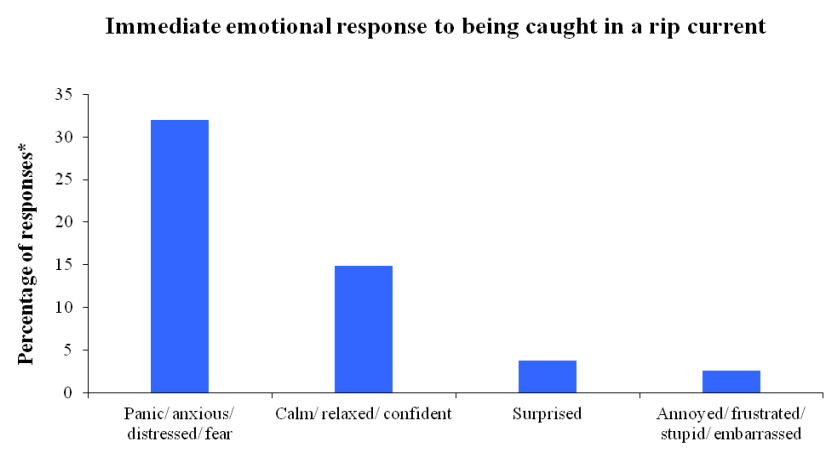

Fig. 8. Emotional responses to being caught in the rip current $(n=$ $665) .{ }^{*}$ These results are based on the frequency of coded themes for Q21, and are represented as a percentage of the total no. of valid responses. Respondents' responses could have been coded into more than one theme.

Respondents were also asked to remember and describe their immediate response to being caught in the rip current. Responses to this question were grouped according to whether they were primarily physical (381 responses) or emotional (354 responses), themes were identified using the same latent coding technique. The most common physical response was to "swim against the rip/toward the shore" (130 cited responses) (Fig. 7). Not only can this option potentially exhaust swimmers, it contradicts respondent's prior safety knowledge (Fig. 3).

Other respondents recalled an immediate emotional response to being caught in a rip current, the most common being "panic, anxiousness, nervousness, distress or fear". Notably, a larger number of respondents cited an emotional response of panic than a physical response of attempting to swim out of the rip (Fig. 8).
Table 3. Variables that influenced whether a respondent raised their arm for help.

\begin{tabular}{llll}
\hline & \multicolumn{3}{l}{ Did you raise your arm? } \\
\cline { 2 - 4 } & No & Yes & TOTALS \\
\hline Can you ID a rip current? & & & \\
\hline No & 74 & 30 & 104 \\
Yes & 464 & 98 & 562 \\
TOTALS (no. of responses) & $\mathbf{5 3 8}$ & $\mathbf{1 2 8}$ & $\mathbf{6 6 6}$ \\
\hline How often do you swim at the beach? & & & \\
\hline Everyday & 76 & 16 & 92 \\
1-3 times a week & 182 & 36 & 218 \\
More than 3 times a week & 101 & 17 & 118 \\
1-3 times a month & 97 & 33 & 130 \\
More than 3 times a month & 50 & 11 & 61 \\
Outside of summer/other times of year & 36 & 15 & 51 \\
TOTALS (no. of responses) & $\mathbf{5 4 3}$ & $\mathbf{1 2 8}$ & $\mathbf{6 7 1}$ \\
\hline How would you rate your swimming ability? & & & \\
\hline One - unable to swim & 6 & 2 & 8 \\
Two & 22 & 14 & 36 \\
Three & 147 & 42 & 189 \\
Four & 201 & 48 & 249 \\
Five - highly competent & 167 & 22 & 189 \\
TOTALS (no. of responses) & $\mathbf{5 4 3}$ & $\mathbf{1 2 8}$ & $\mathbf{6 7 1}$ \\
\hline
\end{tabular}

\subsubsection{Escaping the rip current}

To establish how the respondents escaped the rip current, a series of questions relating to their escape tactics were asked. In these questions, respondents were asked whether they selfrescued or sought help, how they attempted to swim out of the current and whether they recalled any specific rip current safety message while they were caught.

An overwhelming 83 percent of respondents indicated that they escaped the rip current without any form of assistance. Only 6 percent of respondents were rescued by a lifeguard, while 11 percent of respondents were rescued or assisted by another person who was not a lifeguard or lifesaver. To determine the factors that contributed to this high number of self-escapees, cross tabulations were run using age, swimming ability and frequency and a respondent's capacity to identify a rip, as independent variables. The oldest respondents (65 yr and older) were much more likely to raise their arm to signal for help (39 percent of responses) when caught in a rip current than those 18 to $25 \mathrm{yr}$ of age (16 percent of responses). Respondents who could identify a rip current were also less likely (15 percent of responses) to raise their arm for help if caught in a rip current (Table 3). A respondent's selfrated swimming ability did influence the frequency at which respondents signalled for help. Poor swimmers were more likely to signal for help. However, there was little indication that swimming frequency influenced a respondent's decision to signal for help when caught in a rip current (Table 3). These results suggest an apparent complacency about being able to actually identify a rip and the ability to escape a 


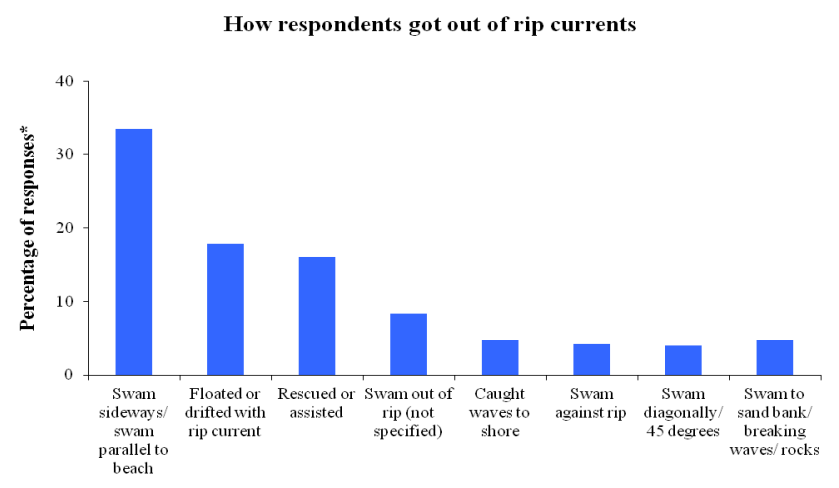

Fig. 9. How respondents got out of the rip current $(n=549) .{ }^{*}$ These results are based on the frequency of coded themes for Q26, and are represented as a percentage of the total no. of valid responses. Each response for this question was only coded once.

rip current without the assistance of lifeguards or lifesavers. The results supports Sherker et al.'s (2008) finding that many beachgoers deliberately ignore swim safety advice messages and others simply do not appear to perceive the danger associated with the rip current hazard.

Respondents who self-escaped from the rip current used a variety of methods (Fig. 9). The two most common methods cited were to "swim sideways/parallel to the beach", or to "drift/float with the rip". These correlate with the two most commonly cited rip current response safety methods (Fig. 4) and indicate that some respondents used their knowledge of rip current escape messages to good effect in the water.

Respondents were also asked if they remembered a beach safety message while they were caught in the rip. Sixtythree percent of respondents said they recalled a beach safety message. The most frequently recalled message was "swim across rip/parallel to the beach" (34 percent of responses) (Fig. 10). This result indicates that a large number of respondents did exactly what they remembered to do, and indicates the potential effectiveness of a consistent beach safety message. The next two most common responses were "Don't panic/remain calm" (24 percent of response) and "Don't swim against the rip" (22.5 percent of responses). These results show that despite knowing not to panic and not to swim against the rip current, their physical and emotional responses (Figs. 7 and 8) when caught in the rip current appear to have overridden a more informed response. The inference here reflects the onset of panic overriding a more rational recollection of appropriate safety messages and a desire to get back to the beach. For example, some respondents commented:

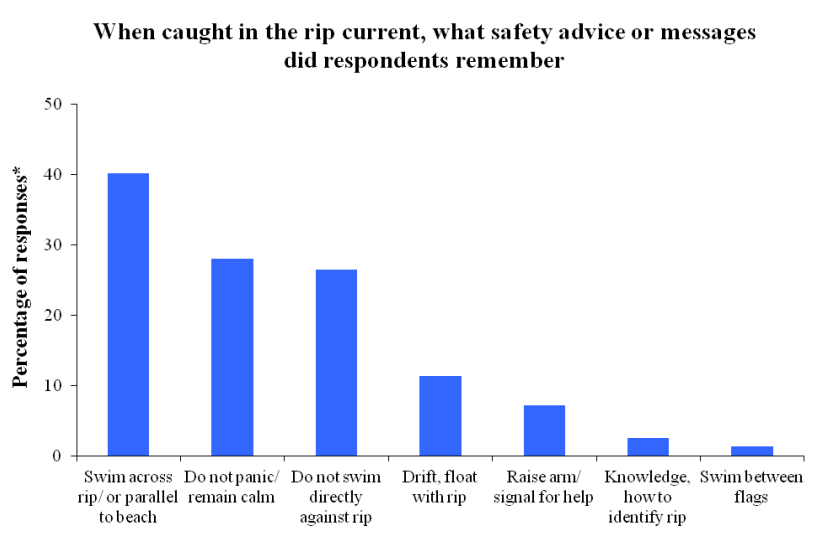

Fig. 10. When caught in the rip current, what safety advice or messages did respondents remember? $(n=431)$. ${ }^{*}$ These results are based on the frequency of coded themes for Q27, and are represented as a percentage of the total no. of valid responses. Respondents' responses could have been coded into more than one theme.

I was terrified and couldn't think straight (I did know what to do, but couldn't put it into practice)...I had the immediate response to swim towards the beach. Then realising I wasn't getting closer, the panic set in (Respondent \# 707, paper survey).

I panicked and forgot everything I knew about what to do in a rip (Respondent \# 139, 21 January 2011).

\subsection{Retrospection}

Respondents were asked if they would react differently to being caught in a rip current in retrospect. Just over half (56 percent of respondents) indicated they would not react differently if they were caught in a rip current again. Conversely, of the 44 percent of respondents who said they would react differently, the most commonly cited response was that next time they would "stay calm, and don't panic". A correlation between this question and what rip current safety advice they had remembered (Fig. 4) showed that people that had remembered safety advice were more likely not to respond differently if caught in a rip current again. This outcome highlights the importance of appropriate beach safety knowledge messages that people are comfortable with through experience.

Despite being caught in a rip current, 85 percent of respondents said the experience did not deter them from swimming in the ocean again suggesting that the overall experience was not exceedingly traumatic for most. This may be related to the high self-escape rate, swimming ability and rip knowledge of this particular group of respondents.

\subsection{Is there an achievable rip current safety message?}

People caught in rip currents respond and react in different ways due to multiple factors. Each respondent's rip current 
Table 4. Sequence of rip current response messages during respondents' rip current experiences.

\begin{tabular}{|c|c|c|c|}
\hline & \multicolumn{3}{|c|}{ Most popular responses } \\
\hline & 1 & 2 & 3 \\
\hline $\begin{array}{l}\text { Message remembered before } \\
\text { caught in rip currents (Fig. 3) }\end{array}$ & Swim sideways to rip/parallel to beach & Float with rip current & Don't panic/remain calm \\
\hline $\begin{array}{l}\text { Message remembered when } \\
\text { caught in rip currents (Fig. 10) }\end{array}$ & Swim across rip/parallel to beach & Don't panic/remain calm & Don't swim directly against rip \\
\hline $\begin{array}{l}\text { Immediatephysical response } \\
\text { when caught in rip currents } \\
\text { (Fig. 7) }\end{array}$ & Swim against rip to shore & Swim across rip/parallel to beach & Drift, float with rip current \\
\hline $\begin{array}{l}\text { Immediate emotional } \\
\text { response when caught } \\
\text { in rip current (Fig. 8) }\end{array}$ & Panic/anxious/distressed/fear & Calm/relaxe/confident & Surprised \\
\hline $\begin{array}{l}\text { How respondents got out } \\
\text { the rip current (Fig. 9) }\end{array}$ & Swam sideways/parallel to beach & Drifted, floated with rip current & Rescued or assisted \\
\hline Suggested safety message & Stay calm/don't panic & Knowledge of how to identify the rip & Seek help/raise arm \\
\hline
\end{tabular}

experience was based on a range of context-specific factors: e.g. their swimming ability, history of swim training, age and type of beach they visited. Their recollection of beach safety messages also varied before, during and after their rip current experience (Table 4). These multiple factors and the variability of responses shown in the results highlight the challenges and limitations involved in promoting a single archetypal rip current safety message. While it is clear that multiple messages exist regarding how a swimmer should respond when caught in a rip, the dominant message amongst this cohort was to escape a rip by swimming parallel, or sideways, to the beach. However, when actually caught in the rip current, the dominant response was to swim against the rip back to shore and to panic (Fig. 8). In retrospection, the respondents view had clearly changed from an active response (swim parallel) to a passive response of "don't panic", which is how most respondents reacted emotionally when caught in the rip current.

Drawing on respondent's answers to the question "what type of education message do you think would best equip someone with the knowledge and skills to get out of the rip current?", the "stay calm and don't panic" message was most commonly endorsed, as evident in these respondent's comments:

The most important thing is not to panic...the rip will not go on forever (Respondent \# 39, 20 January, 2011).

Don't panic....If not a strong swimmer, raise your arm for assistance from lifeguard' (Respondent \# 33, 20 January, 2011).

Don't panic - as soon as you do, you lose energy and focus.... I believe the reason people drown more often than not (even in really shallow water) is because they panic and lose their breath' (Respondent \# 34, 20 January, 2011).
The inference from these findings suggests that future rip current education and awareness programs should focus on promoting the "don't panic" message. While most existing rip current education programs and campaigns already incorporate this message to some degree (Brander and McMahan (2011), it is not always emphasised as the primary message. For example, Surf Life Saving Australia's preference in their recent national rip current education campaign is for a primary prevention message of "swim between the red and yellow flags". The aim here is to first get swimmers to choose a safer location to swim, before emphasising a secondary prevention message of "stay calm, float and raise an arm for attention" (www.ripcurrents.com.au).

The survey respondents also indicated that improved beach signage, further knowledge related to rip current identification, and emphasis on raising an arm to signal for help should be endorsed in rip current safety material:

Perhaps provide clear \& concise info at the beach (signage) e xplaining how identify \& how to get out of a rip current (Respondent \# 434, 31 January, 2011).

More signage on the beach. Maybe even fliers on a bad busy day (Respondent \#152, 21 January, 2011).

Better beach signage. People not accustomed to surf beaches should be warned at beach entry points. Lifeguards should offer information - flyers would be a start. Group info sessions twice a day for 5 minutes at lifeguard tower would also be good. This could be noted on the signs (Respondent \# 95, 20 January, 2011).

Of note, these three beach safety messages were cited in more responses than the methods of rip current response swim parallel to the beach and stay afloat - that are now being debated (Brander and McMahan, 2011). The implication here is that after experiencing being caught in a rip current, 
the survey respondents saw the value in adopting a more preventative approach to rip current education strategies.

\section{Conclusions}

This paper details the results of a pilot study that surveyed people who have been caught in a rip current and survived. It is the first study to quantitatively assess the knowledge and responses of people who have actually experienced the rip current hazard. The research sample was an informed group. The majority were predominantly good swimmers, frequent ocean swimmers and were competent at visually identifying rip currents. While this informed cohort potentially presents a biased sample, it exposes an intriguing outcome. Despite their experience and knowledge, these informed respondents still got caught in rip currents and panicked.

While mixed messages exist regarding how to respond when caught in a rip current, the active response of "swimming parallel to the beach" was the most commonly remembered message. This result suggests that swimming parallel to the beach presented a viable option to escape the rip current for confident ocean swimmers. However, in retrospect, most respondents indicated an improved need to promote the passive response "don't panic" as the primary education message for future rip education strategies in lieu of an active response such as "swim parallel". They also suggested the use of improved education of rip current behaviour and identification, particularly on the beach.

This study has demonstrated that much more information about rip current survivors and their rip current experience needs to be obtained, particularly for less competent swimmers, and more infrequent beach users. The people who responded to our online surveys were likely to be interested in beaches and beach safety given the dissemination outlets. More intensive traditional sampling on the beach would yield a greater diversity of respondents with more variable demographics, swimming ability and surf safety knowledge. Furthermore, many of the questions in this survey can be modified and adapted to suit specific target audiences such as international tourists or specific demographic groups. For example, additional questions about the length of residence in Australia of overseas-born respondents may help in explaining the similarities and potential differences in beach safety knowledge among Australian and overseas-born beachgoers.

Almost all the respondents were caught in rip currents because they chose to swim outside of patrolled areas or on unpatrolled beaches. This paper has shown this to be a reflection of both their swimming experience and overconfidence in assessing the potential risk of the rip current. This research provides an important reminder that future rip current education and awareness strategies should adopt a dual focus and seek innovative methods to motivate experienced swimmers to swim in patrolled locations, while also educating inexperienced swimmers of the rip current hazard. Such a detailed educational focus is necessary given that within an informed group of experienced swimmers, knowledge of how to identify a rip current did not necessarily translate into a parallel recognition of the potential dangers of the rip current. Clearly, experienced swimmers still get into trouble on surf beaches. This warrants further research into how to overcome such an apparent complacency and overconfidence about the rip current hazard and the challenges of rip current identification. It is also a timely reminder about the importance of beach safety to all beachgoers, regardless of experience.

Acknowledgements. We would like to thank Surf Life Saving Australia (SLSA) for the funding to support this study and for ABC Radio for promoting the online survey. DDH and JG thanks the UNSW for funding via the award of the SPF01 grant. The questionnaire survey instrument is available on request from the corresponding author.

Edited by: S. Tinti

Reviewed by: two anonymous referees

\section{References}

ABS: Standard Australian Classification of Countries (SACC), 1998 (Revision 2.03), 2008.

Ballantyne, R., Carr, N., and Hughes, K.: Between the flags: an assessment of domestic and international university students' knowledge of beach safety in Australia, Tourism. Manage., 26, 617-622, 2005.

Bazeley, P.: Qualitative Data Analysis with NViVO, Sage Publications, 2007.

Bird, D. and Dominey-Howes, D.: Tsunami risk mitigation and the issue of public awareness, The Australian Journal of Emergency Management, 21, 29-35, 2006.

Bird, D. and Dominey-Howes, D.: Testing the use of a "questionnaire survey instrument" to investigate public perceptions of tsunami hazard and risk in Sydney, Australia, Nat. Hazards, 45, 99-122, 2008.

Brander, R. W. and MacMahan, J. H.: Future challenges for rip current research and outreach, in: Rip Currents, Beach Safety, Physical Oceanography and Wave Modeling, edited by: Leatherman, S. and Fletemeyer, J., CRC Press, Boca Raton, FL., 1-29, 2011.

Brander, R. W., Bradstreet, A., Sherker, S., and MacMahan, J.: The behavioural responses of swimmers caught in rip currents: new perspectives on mitigating the global rip current hazard, International Journal of Aquatic Research and Education, 5, 476-482, 2011.

Dalrymple, R. A., MacMahan, J. H., Reniers, A. J. H. M., and Nelko, V.: Rip currents, Ann. Rev. Fluid Mech., 43, 551-581, 2011.

Dominey-Howes, D. and Goff, J.: Tsunami: unexpected blow foils flawless warning, Nature, 464, 350, 2010.

Fletemeyer, J. and Leatherman, S.: Rip currents and beach safety education, J. Coast. Res., 26, 1-3, 2010.

Gensini, V. and Ashley, W.: Examination of rip current fatalities in the United States, Nat. Hazards, 54, 159-175, 2010. 
Houser, C., Barrett, G., and Labude, D.: Alongshore variation in the rip current hazard at Pensacola Beach, Florida, Nat. Hazards, 57, 501-523, 2011.

MacMahan, J. H., Thornton, E. B., and Reniers, A. J. H. M.: Rip current review, Coast. Eng., 53, 191-208, 2006.

MacMahan, J., Brown, J., Brown, J., Thornton, E., Reniers, A., Stanton, T., Henriquez, M., Gallagher, E., Morrison, J., Austin, M. J., Scott, T. M., and Senechal, N.: Mean lagrangian flow behaviour on an open coast rip-channelled beach: a new perspective, Mar. Geol., 268, 1-15, 2010.

MacMahan, J., Reniers, A., Brown, J., Brander, R., Thornton, E., Stanton, T., Brown, J., and Carey, W.: An introduction to rip currents based on field observations, J. Coast. Res., 27, iii-vi, 2011.

McCool, J., Moran, K., Ameratunga, S., and Robinson, E.: New Zealand Beachgoers' swimming behaviours, swimming abilities, and perception of drowning risk, International Journal of Aquatic Research and Education, 1, 7-15, 2008.

McCool, J., Ameratunga, S., Moran, K., and Robinson, E.: Taking a risk perception approach to improving beach swimming safety, Int. J. Behav. Med., doi:10.1007/s12529-009-9042-8, 2009.

Miloshis, M. and Stephenson, W.: Rip current escape strategies: lessons for swimmers and coastal rescue authorities, Nat. Hazards, 59, 823-832, 2011.
Moran, K.: Water safety knowledge, attitudes and behaviours of Asian youth in New Zealand, Proceedings of the 2nd International Asian Health and Wellbeing Conference, Auckland, New Zealand, 91-101, 2006.

Moran, K.: Will they sink or swim? New Zealand youth water safety knowledge and skills, International Journal of Aquatic Research and Education, 2, 114-127, 2008.

Morgan, D., Ozanne-Smith, J., and Triggs, T.: Descriptive epidemiology of drowning deaths in a surf beach swimmer and surfer population, Injury Prevention, 14, 62-65, 2008.

Sherker, S., Brander, R., Finch, C., and Hatfield, J.: Why Australia needs an effective national campaign to reduce coastal drowning. Journal of Science and Medicine in Sport, 11, 81-83, 2008.

Sherker, S., Williamson, A., Hatfield, J., Brander, R., and Hayen, A.: Beachgoers' beliefs and behaviours in relation to beach flags and rip currents, Accident Anal. Prev., 42, 1785-1804, 2010.

Short, A. D.: Australian rip systems -friend or foe?, J. Coast. Res., SI 50, 7-11, 2007.

SLS (Surf Life Saving Australia), National Coastal Safety Report 2011: A Summary of Coastal Drowning Deaths in Australia, 2011.

Wilks, J., DeNardi, M., and Wodarski, R.: Close is not enough: drowning and rescues outside flagged beach patrol areas in Australia, Tourism in Marine Environments, 4, 57-62, 2007. 